This item was submitted to Loughborough's Research Repository by the author.

Items in Figshare are protected by copyright, with all rights reserved, unless otherwise indicated.

\title{
Morphological and mechanical properties of blades of Saccharina latissima
}

PLEASE CITE THE PUBLISHED VERSION

http://dx.doi.org/10.1016/j.ecss.2017.06.033

\section{PUBLISHER}

(c) Elsevier

VERSION

AM (Accepted Manuscript)

\section{PUBLISHER STATEMENT}

This work is made available according to the conditions of the Creative Commons Attribution-NonCommercialNoDerivatives 4.0 International (CC BY-NC-ND 4.0) licence. Full details of this licence are available at: https://creativecommons.org/licenses/by-nc-nd/4.0/

\section{LICENCE}

CC BY-NC-ND 4.0

\section{REPOSITORY RECORD}

Vettori, Davide, and Vladimir Nikora. 2019. "Morphological and Mechanical Properties of Blades of Saccharina Latissima". figshare. https://hdl.handle.net/2134/25844. 


\section{Morphological and mechanical properties}

\section{2 of blades of Saccharina latissima}

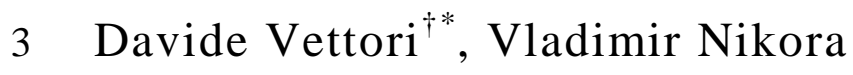

4 School of Engineering, University of Aberdeen, Aberdeen, AB24 3UE, Scotland, UK

$5+$ Current address: Department of Geography, Loughborough University, Loughborough, LE11 3TU, UK

6 *Corresponding author (email: d.vettori@lboro.ac.uk)

7 Abstract

8 Interactions between water flow and aquatic vegetation strongly depend on morphological

9 and biomechanical characteristics of vegetation. Although any physical or numerical model

10 that aims to replicate flow-vegetation interactions requires these characteristics, information

11 on morphology and mechanics of vegetation living in coastal waters remains insufficient. The

12 present study investigates the mechanical properties of blades of Saccharina latissima, a

13 seaweed species spread along the shores of the UK and North East Atlantic. More than 50

14 seaweed samples with lengths spanning from $150 \mathrm{~mm}$ to $650 \mathrm{~mm}$ were collected from Loch

15 Fyne (Scotland) and tested. Seaweed blades had a natural 'stretched droplet' shape with

16 bullations in the central fascia and ruffled edges in the area close to the stipe. Their

17 morphological features showed high variability for samples longer than $400 \mathrm{~mm}$. The blades

18 were almost neutrally buoyant, their material was found to be very flexible and ductile, being

19 stiffer in longer blades. The laboratory tests showed that estimates of tensile Young's

20 modulus appeared to be similar to bending Young’s modulus suggesting a reasonable degree

21 of isotropy in studied seaweed tissues.

22 Keywords: 
23 Brown alga; organism morphology; mechanical properties; elasticity; Saccharina latissima;

24 Scotland

\section{Introduction}

In recent years, vegetation in coastal waters has been investigated for various applications. For example, it has been found to contribute to reduction of flow velocity (Fonseca and Koehl, 2006) and attenuation of waves (Möller et al., 1999; Sánchez-González et al., 2011), thus providing means for bio-inspired coastal management (e.g. Temmerman et al., 2013). Another example relates to macroalgae, also referred to as seaweeds, which are among most common vegetation in coastal waters. They were employed in the Integrated Multi-Trophic Aquaculture (IMTA) (Chan et al., 2006; Chopin and Sawhney, 2009, Lamprianidou et al., 2015) and were proposed for bioremediation purposes (Fei, 2004; Mata et al., 2010). A number of studies have also assessed the feasibility of seaweeds for the production of third generation bio-fuels (Hughes et al., 2012; Wargacki et al. 2012). In addition, seaweeds are a traditional source of food in East Asia (e.g. China, Japan, and South Korea), where they have been cultivated for centuries (Bardach et al., 1972). Nowadays seaweed farming is mainly confined to East Asia, because standard cultivation techniques necessitate a high amount of manual work and the associated costs are too high (Lucas and Southgate, 2012). The cultivation of seaweeds is expected to experience a continued expansion, prompted by the wide use of seaweed-derived components such as the hydrocolloids (Lucas and Southgate, 2012). This expansion, however, is conditioned by the development of innovative farming techniques that would make seaweed farming economically attractive (James, 2010).

Novel farming techniques and any of the above applications have to be supported by either numerical or physical modelling that requires a comprehensive understanding of the 
flow-seaweed interactions at a relevant range of spatial scales. These interactions control physical, biological and ecological phenomena concerning aquatic vegetation, and depend upon their morphological and mechanical properties (Nikora, 2010). In order to describe the motion of any streamlined body in flowing water, it is sensible to start with simple geometry considering a seaweed blade as a two-dimensional beam. For any type of application, the motion of the blade can then be described by an equation of motion such as:

$$
\frac{m}{l} \frac{\partial^{2} z}{\partial t^{2}}-T \frac{\partial^{2} z}{\partial x^{2}}+E I \frac{\partial^{4} z}{\partial x^{4}}=F_{F}
$$

where $m$ is the body mass, $l$ is the body length, $x$ and $z$ are the longitudinal and vertical coordinates, $t$ is time, $T$ is the axial tension in the body, $E$ is Young's modulus of the material of which the body is made, $I$ is the second moment of area of the body and $F_{F}$ accounts for the forces per unit length acting on the body due to the flow action (e.g. Païdoussis, 1998; Connell and Yue, 2013). The first term in Eq. (1) represents inertia, the second term relates to the tensile force, and the third term is due to the bending force. Altogether these forces balance the forces imposed by flowing water, i.e., the total (viscous and pressure) drag force $F_{F}$. Equation (1) and its variants are involved in up-scaled models describing seaweed performance at a canopy scale and larger scales relevant to seaweed management and cultivation.

The second and third terms in Eq. (1) contain parameters characterising mechanical properties of the body. In addition, all four terms are influenced by the body morphology. It is, therefore, clear that the knowledge of mechanical and morphological properties of aquatic vegetation is of primary importance for understanding and predicting flow-vegetation interactions and, consequently, advancing the knowledge of their multiple effects. Reliable physical and numerical models for prediction of vegetation effects on the coastal flows and of 
vegetation performance in a variety of applications (e.g. IMTA, bioremediation, cultivation) can be developed only if relevant data on vegetation are available. In the literature, information on the mechanics and morphology of aquatic vegetation remains sparse. Mechanical data of seaweed tissues are provided by very few publications (Biedka et al., 1987; Hale, 2001; Harder et al., 2006; Boller and Carrington, 2007; Paul et al., 2014). Thus, for the development of reliable models concerning any aspect of flow-seaweed interactions, the obtaining of such data remains a priority task.

The present study focuses on Saccharina latissima, a seaweed species thriving along the shores of the North East Atlantic (Ramos et al., 2012). Studies of this species for the development of IMTA (Sanderson, 2006) and for bioethanol production (Wargacki et al., 2012) produced promising results. Therefore, the research reported in this paper aims at contributing to the knowledge of morphological and mechanical properties of coastal vegetation in relation to $S$. latissima. Section 2 is focused on methodological issues of the study, while section 3 reports and discusses the key results in relation to seaweed blade morphology and mechanical properties, keeping in mind the hydraulic conditions at the collection site.

\section{Materials and methods}

\subsection{Seaweed collection and storage}

Samples of S. latissima were collected with the help of Loch Fyne Oysters Limited on the $10^{\text {th }}$ of February 2015 from long-lines deployed in Loch Fyne (Scotland). The coordinates of the collection site are $56.08 \mathrm{~N}$ and $5.28 \mathrm{~W}$ (Fig. 1). Due to the loch morphology, the most important forcing factors in the loch hydrodynamics are tides. Existing current meter data sets can provide useful information to characterise the hydraulic conditions within Loch Fyne and at the collection site. The data set used in this study (available at http://www.bodc.ac.uk) 
were recorded with an Aanderaa RCM 7/8 Recording Current Meter mounted on a subsurface mooring approximately $10 \mathrm{~km}$ North East of the collection site (Fig. 1). The characteristics of the current meter data set and the bulk statistics of the current velocity calculated by the authors are reported in Table 1 . The selected collection site on the loch can be considered to be sheltered and thus hydraulic conditions at this site may be biased low compared to the flowmeter deployment site (Fig. 1).

Table 1 Information about the current velocity data set recorded with a current meter in Loch Fyne and current velocity statistical parameters calculated by the authors. (2 columns)

\begin{tabular}{lc|lc}
\hline \multicolumn{2}{l|}{ Characteristics of current velocity data set } & \multicolumn{2}{l}{ Current velocity parameters } \\
\hline Location of current meter & $56.15 \mathrm{~N}, 5.15 \mathrm{~W}$ & & \\
Number of samples & 4656 & Mean (cm/s) & 11.1 \\
Start date (dd/mm/yy h:mm) & $20 / 11 / 199412: 00$ & Min. value (cm/s) & 1.4 \\
End date (dd/mm/yy h:mm) & $25 / 02 / 199510: 00$ & Max. value (cm/s) & 57.8 \\
Sampling interval (s) & 1800 & Stand. Dev. (cm/s) & 8.4 \\
Sea floor depth (m) & 100 & Skewness & 1.3 \\
Current meter depth (m) & 11 & Kurtosis & -0.7 \\
\hline
\end{tabular}

Prior to collection, seaweeds were visually inspected to assess their condition. Only seaweeds showing no signs of damage or deterioration and with no visible bryozoans on their surface were collected, their holdfasts then were removed and they were stored in tanks filled with seawater. Seaweeds were transported to the University of Aberdeen and placed into a special storage container within 8 hours after collection. The storage container was a $125 \mathrm{l}$ tank filled with seawater and equipped with a custom-made aeration system. The seawater in

107 the container was changed every 3-4 days according to the standard practice for seaweed storage in tanks with no recirculating flow (Frithjof Kuepper, University of Aberdeen, pers. comm., September 2014). The tank was kept outdoor so that water temperature was as close

110 to the ambient temperature as possible and seaweeds were exposed to natural light conditions

111 (i.e. 8 h:16 h day:night cycle). Seaweeds were visually monitored on a daily basis to assess 
112 their condition. The blades that showed visible signs of deterioration were discarded. All 113 seaweeds were used within 14 days after collection.

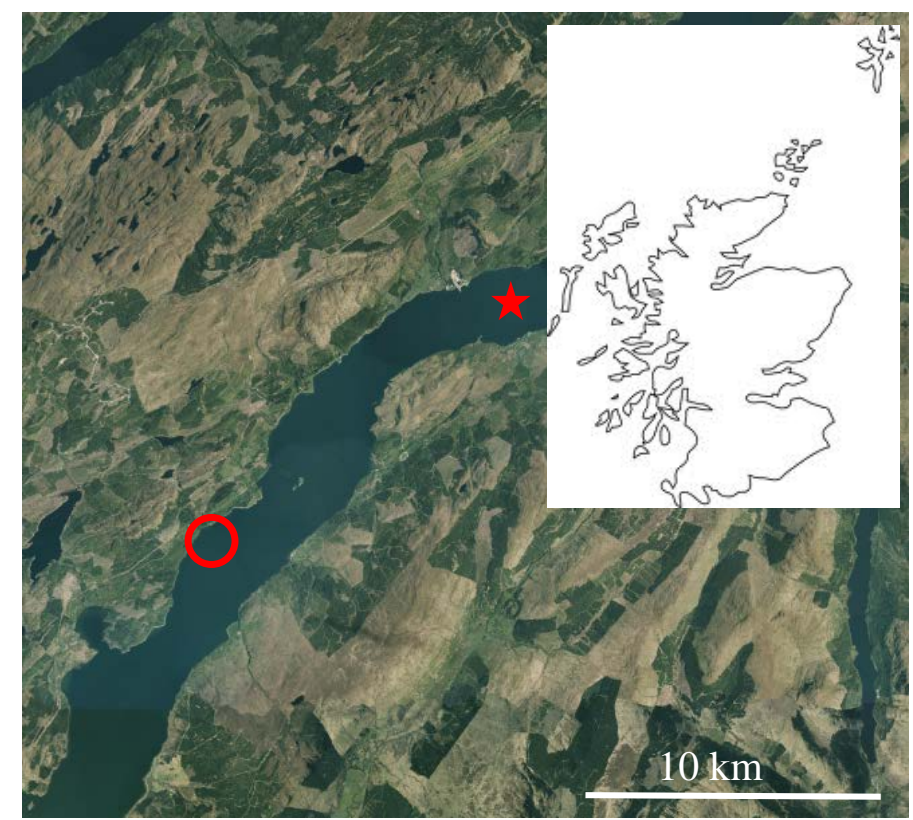

Fig. 1 The collection site in Loch Fyne is located in the area identified with a circle. The star represents the location of deployment of the current meter. The inset map (top right) shows the location of Loch Fyne in Scotland (adapted from http://digimap.edina.ac.uk/). (1.5 column)

\subsection{Morphological assessment}

At a first step, the stipe was detached from the seaweed sample. Then, the seaweed blade was carefully dried with paper towels and weighed using a digital scale (OHAUS GT 2100 or Mettler P161, Mettler Toledo, Columbus, USA). Photos of the sample were taken with a digital camera (Fujifilm Finepix S1000fd, Fujifilm, Tokyo, Japan) on a light table (Illuma System, Bencher Inc., Chicago, USA). From the photos, seaweed blade projected $A_{\text {proj }}$ and full-one-side $A_{\text {real }}$ surface areas were evaluated using MATLAB ${ }^{\circledR}$ image processing tools. The projected surface area of a blade was estimated as the plane surface area covered by the blade on the light table. The full-one-side surface area of a blade was estimated taking into 
account any folded parts of the blade that resulted in an overlapping on the light table (see Vettori, 2016 for complete description of methods). scales: length $l$, average $w_{\text {mean }}$ and maximum $w_{\max }$ widths, and thickness $t$. The average width was obtained as a ratio of the projected area on the blade length. As thickness varied across and along the blade, it was measured at the centre and edges of the blade at the

134 following distances from the juncture of stipe and blade: $2 \mathrm{~cm}, 0.25 l, 0.5 l, 0.75 l$. The minimum $t_{\min }$ and maximum $t_{\max }$ thicknesses were recorded. The volume $V$ of the seaweed blade was measured by immersing it in a measuring cylinder partially filled with unfiltered freshwater at room temperature. After these measurements were taken, the seaweed blade was stored in seawater again prior to preparation of specimens to perform mechanical tests.

\subsection{Mechanical testing}

140 Mechanical tests were performed on specimens cut from 14 seaweed blades of various lengths. Two types of mechanical tests were completed: uniaxial tensile tests using a bench top testing machine (Fig. 2a); and bending tests using a Peirce’s testing apparatus (Fig. 2b). Mechanical tests were conducted on specimens sliced from seaweed blades after their

144 morphological measurements were completed (section 2.2). The specimens were cut from the

145 central fascia of the blades to minimise the presence of undulations that could affect the 146 mechanical tests. They were sliced along the blades in such a way that they never contained 147 nicks or flaws, which would affect their mechanics. Furthermore, in order to prevent 148 significant end-wall effects, the specimens were prepared with a length to width ratio equal to 149 or higher than 10 (Niklas, 1992). Specimens were typically $100 \mathrm{~mm}$ long and 5-7 mm wide if 150 used in tensile tests, and $200 \mathrm{~mm}$ long and $20 \mathrm{~mm}$ wide if used in bending tests. For bending tests to be conducted successfully, the use of longer specimens was required. This restriction 
152 reduced the number of specimens that could be tested from each seaweed blade compared to

153 those used for tensile tests. After being prepared and prior to the mechanical tests, specimens

154 were stored in seawater.

155 Uniaxial tensile tests were conducted with a benchtop testing machine (H10K-S UTM,

156 Tinius Olsen, Salfords, UK) with a 100N load cell (HTE, Tinius Olsen, Salfords, UK) (Fig.

157 2a). The machine was equipped with two friction clamps, which could hold specimen ends

158 between a sandpaper plate and a textured sprung cylinder (a complete description can be

159 found in Miler et al., 2012). The force values were measured with a resolution of 1 part in 16032000 with 200 readings per second (Hounsfield Test Equipment, 1997). The relative error of

161 the force reading was determined, via independent calibration, as $1.5 \%$ for force below $2 \mathrm{~N}$

162 and $0.1 \%$ for force above $2 \mathrm{~N}$. The relative error of the displacement readings did not exceed

$163 \quad$ 0.5\% (Miler et al., 2012).

164 For testing seaweed blade specimens, a plate covered by sandpaper was added between

165 the sprung cylinder and the specimen at each of its ends in order to minimise the probability

166 of damage of specimen ends. The use of the additional sandpaper plates allowed the pressure

167 of the cylinder to be distributed on a wider area of the specimen, rather than squeezing a

168 narrow cross-section. Two types of tensile tests were carried out: (1) tensile tests up to the

169 breakage point; and (2) tensile cyclic loading-unloading tests. The first type allowed the

170 estimation of material stiffness and strength (Niklas, 1992), while the latter provided

171 information on material resilience to periodic excitations. 


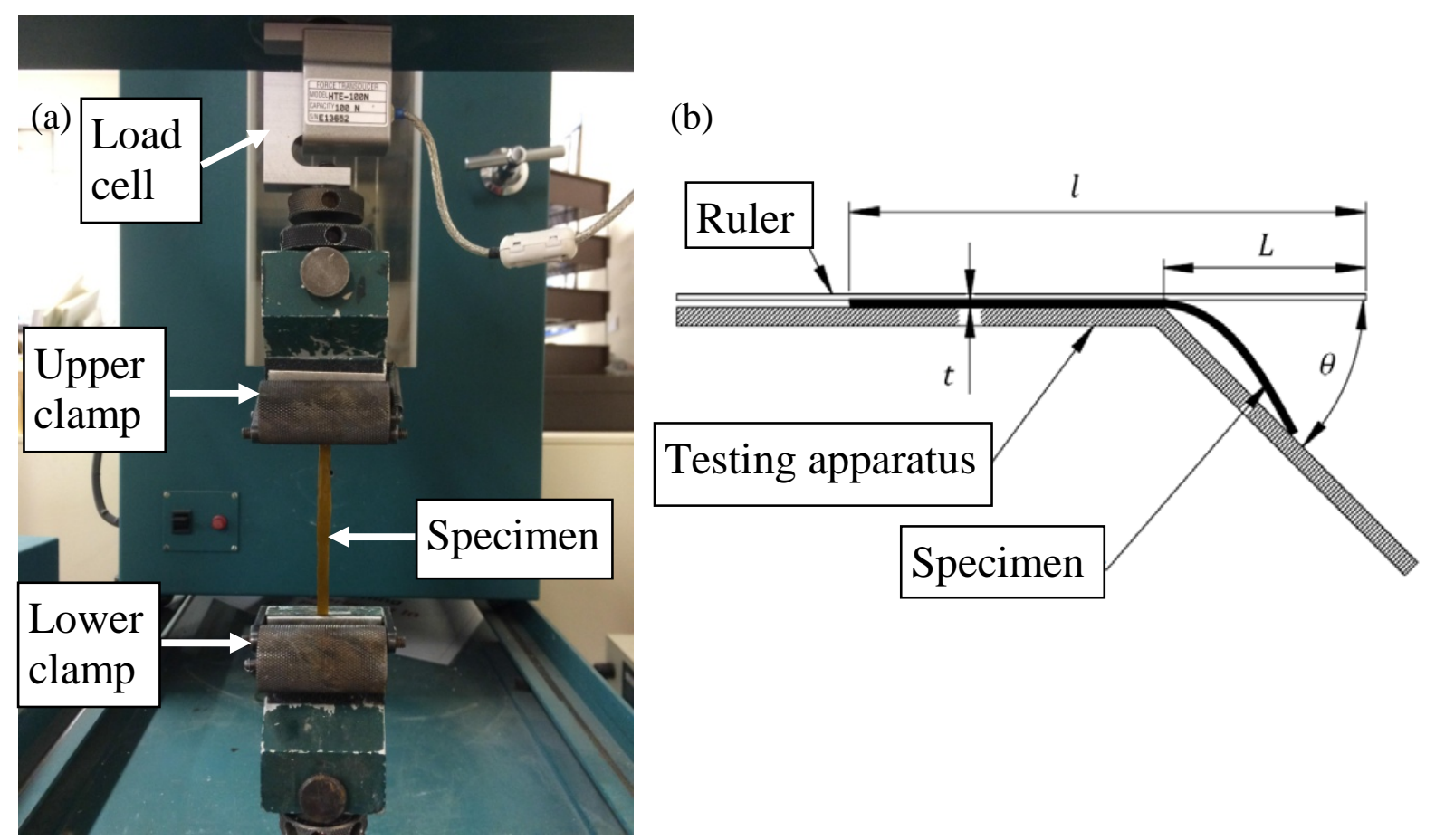

Fig. 2 Hounsfield S-series benchtop testing machine during the testing of a seaweed blade specimen (a). Schematic representation of Peirce's testing apparatus during the testing of a specimen (b) with the definition of the parameters relevant for estimating bending Young's modulus. (2 columns)

During the test, the upper clamp of the machine moved upwards with a constant speed that could be set via dedicated software. The tensile tests were initiated with the clamps located at a distance of $60 \mathrm{~mm}$ from each other. The specimens were stretched at a constant speed set to $20 \mathrm{~mm} / \mathrm{min}$. The 'breakage' tests ended when the specimen failed, while cyclic loading-unloading tests ended after three cycles were completed. During each cycle the specimen was pulled to a displacement threshold of $20 \%$ of its original length, then the upper clamp was returned to its initial position with the same speed (i.e. $20 \mathrm{~mm} / \mathrm{min}$ ). displacement $\delta$ were recorded with a dedicated software (Tinius Olsen, Salfords, UK). For analysis purposes, these data were converted into nominal stress $\sigma$ (i.e. ratio of force to original cross-sectional area of the specimen) and nominal strain $\varepsilon$ (i.e. ratio of displacement to original length of the specimen) values from which biomechanical parameters commonly 
used in plant studies were estimated. The parameters estimated from the tensile tests included: tensile Young's modulus $E_{t}$, i.e. the ratio of $\sigma$ to $\varepsilon$ within a linear region of $\sigma=f(\varepsilon)$; elastic limits $\sigma_{e}$ and $\varepsilon_{e}$; stress $\sigma_{b r}$, force $F_{b r}$ and strain $\varepsilon_{b r}$ at breakage; and toughness $U$. Tensile Young's modulus was calculated as the slope of the initial linear part of the stress-strain curve (i.e. where definition of $E_{t}$ is applicable) (Fig. 3a) by finding the best linear fit using the method of least squares. The elastic limits are the maximum values of stress and strain which limit the range of $\sigma=f(\varepsilon)$ where the material behaves as a linear

194 elastic material (Fig. 3a). The stress, force and strain at breakage represent the maximum

195 values of stress, force and strain reached during a tensile test before the specimen breaks (Fig. 3a). The toughness is the amount of energy per unit volume required for a material to

199 (Fig. 3a), i.e.:

$$
U=\int_{0}^{\varepsilon_{b r}} \sigma d \varepsilon
$$
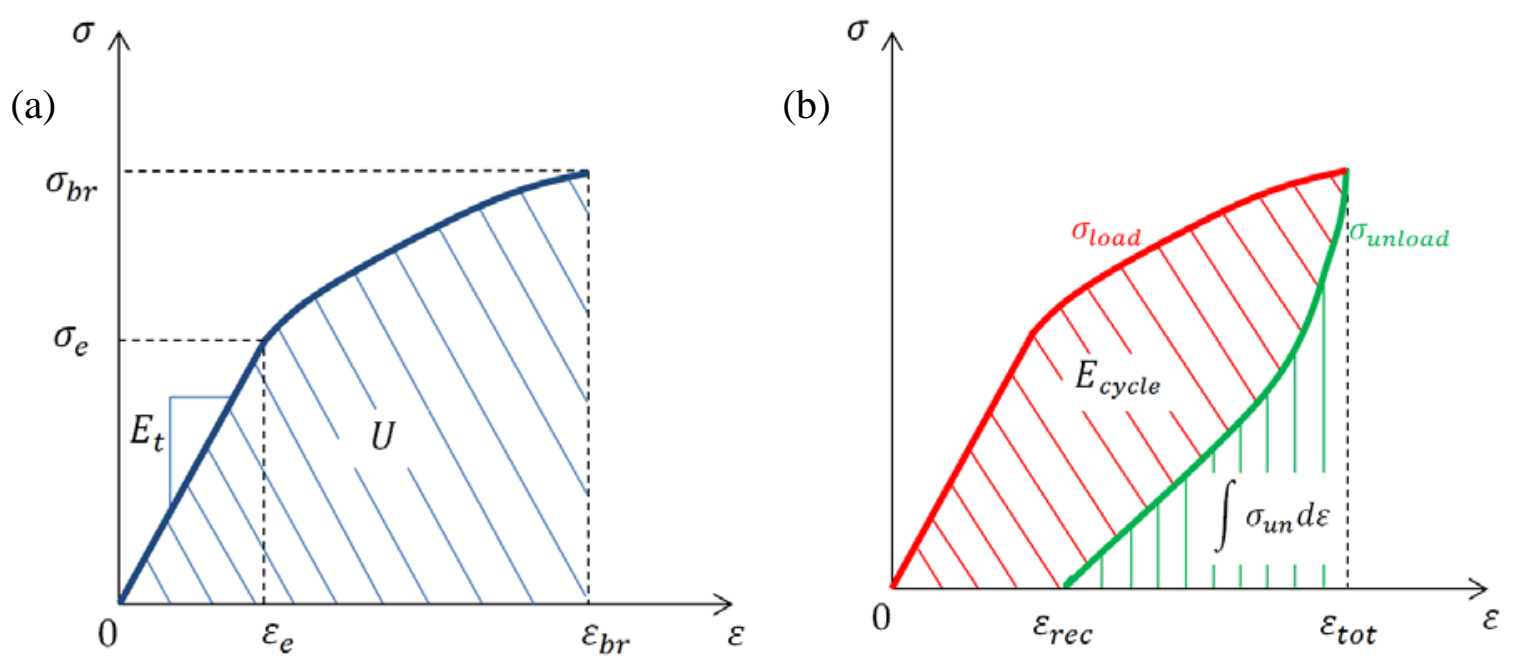
Fig. 3 Representation of stress-strain curves for: tensile test at breakage (a) and tensile cyclic loading-unloading test (b). The

202 diagonal hatched area in (a) is the toughness, the diagonal hatched area in (b) is the elastic hysteresis, and the vertical hatched area in (b) is the amount of energy recovered by the specimen during the unloading phase. (2 columns)

From tensile cyclic tests, three biomechanical parameters were estimated: the elastic calculated using numerical integration by applying the trapezoid method. The elastic hysteresis represents the amount of energy per unit volume used internally by the specimen during a loading-unloading cycle (Niklas, 1992). It is highlighted by the diagonal hatched area in Fig. 3b and is expressed as:

$$
E_{\text {cycle }}=\int_{0}^{\varepsilon_{\text {tot }}} \sigma_{\text {load }} d \varepsilon-\int_{\varepsilon_{\text {rec }}}^{\varepsilon_{\text {tot }}} \sigma_{\text {un }} d \varepsilon
$$

210 The degree of elasticity assesses specimen elongation due to plastic deformations (Niklas, 211 1992). It is the ratio of recovered (elastic) strain to the total strain in a cycle, i.e.:

$$
E_{\varepsilon}=\frac{\varepsilon_{t o t}-\varepsilon_{r e c}}{\varepsilon_{t o t}}
$$

212 where the terms are defined in Fig. 3b. The energy ratio, also referred to as resilience (Niklas, 213 1992), is the ratio of the amount of energy the specimen recovered during the unloading 214 phase to the energy of the loading phase within the same cycle (Fig. 3b), i.e.:

$$
E_{\text {ratio }}=\frac{\int_{\varepsilon_{\text {rec }}}^{\varepsilon_{\text {tot }}} \sigma_{\text {unload }} d \varepsilon}{\int_{0}^{\varepsilon_{\text {tot }}} \sigma_{\text {load }} d \varepsilon}
$$

215 In addition to the tension tests, bending tests were conducted on seaweed blade 216 specimens using a Peirce's testing apparatus (Fig. 2b) manufactured at the University of 217 Aberdeen, with an inclination of the tilted plane $\theta$ of $46^{\circ}$. This device and the theory behind it 
218 are fully described in Peirce (1930) and Henry (2014). At each test, the specimen was located

219 on the flat part of the apparatus, with one end being at its edge. A ruler was placed on the specimen, with its 'zero' located above the specimen edge. Then the specimen and the ruler were pushed towards the tilted part of the apparatus simultaneously. The reading of the cantilever length $L$ (Fig. 2b) was taken as soon as the tip of the specimen touched the tilted part of the device. The test was repeated four times, on both ends of both sides of each specimen, as described by Peirce (1930) and Henry (2014), and the mean value of $L$ was recorded. An estimate of bending Young's modulus $E_{b}$ can then be obtained from $L$ as 226 (Peirce, 1930):

$$
E_{b}=\frac{3}{2} \frac{m g}{l w} \frac{L^{3}}{t^{3}}\left(\frac{\cos (\theta / 2)}{\tan \theta}\right)
$$

where $m$ is the specimen mass; $g$ is gravity acceleration; $l, w$, and $t$ are the length, width and thickness of the specimen, respectively; and the angle $\theta\left(46^{\circ}\right)$ in Fig. $2 \mathrm{~b}$ represents the inclination of the tilted part of the apparatus (Peirce, 1930).

\section{Results and discussion}

\subsection{Blade morphology}

232 The variety of morphological features in seaweed blades has been reported for a number of

233 species. Seaweed blades are generally narrow and flat when growing in an energetic environment and wide with undulated edges when growing in a sheltered environment. Morphological variability was assessed in Gerard (1987) for S. latissima, in Koehl and Alberte (1988) and Koehl et al. (2008) for Nereocystis luetkeana, and in Hurd and Pilditch (2011) for Macrocystis pyrifera. The morphological adaptability in response to environmental conditions is referred to as phenotypic plasticity and is a crucial property of 
240 the collection site, samples of S. latissima in the present study exhibited features that are in agreement with the findings of the studies cited above. Indeed, blades of S. latissima from

242 Loch Fyne were generally wide with undulated edges, as would be expected from samples 243 collected in sheltered areas.

244 Most morphological properties of seaweed blades were found to be dependent on their 245 length, the exception being the minimum thickness, which had an average value of $0.14 \mathrm{~mm}$ 246 (Fig. 4a). Short blades were rather streamlined, while long blades had more complex 247 morphology, with ruffles along the edges. These differences are noticeable in the 248 relationships between the blade length and the blade maximum and average widths (Fig. 4b), 249 the full-one-side and projected surface areas (Fig. 4c), and the blade volume (Fig. 4d). 250 Interestingly, an apparent scale-dependent effect of phenotypic plasticity is also found within 251 the population investigated. For blades shorter than $400 \mathrm{~mm}$, the data exhibit a clear 252 increasing trend with a narrow data collapse. However, for longer blades the data points are 253 spread within a broader range (Fig. 4b-d). This pattern suggests that morphological variability 254 primarily occurs in blades longer than a threshold length (i.e. $400 \mathrm{~mm}$ ), being negligible for shorter blades. In addition, the overall trends revealed in the current study differ from the trends identified by Buck and Buchholz (2005) for blades of S. latissima from an exposed

257 habitat (Fig. 4b-c). Both blade width and surface area increase at a faster rate in the samples 258 analysed in the current study than in those reported by Buck and Buchholz (2005). These results support the idea that hydraulic conditions have a major influence on the morphology of blades of S. latissima, in agreement with Gerard (1987). When growing in a sheltered environment, blades grow wide and ruffled. 

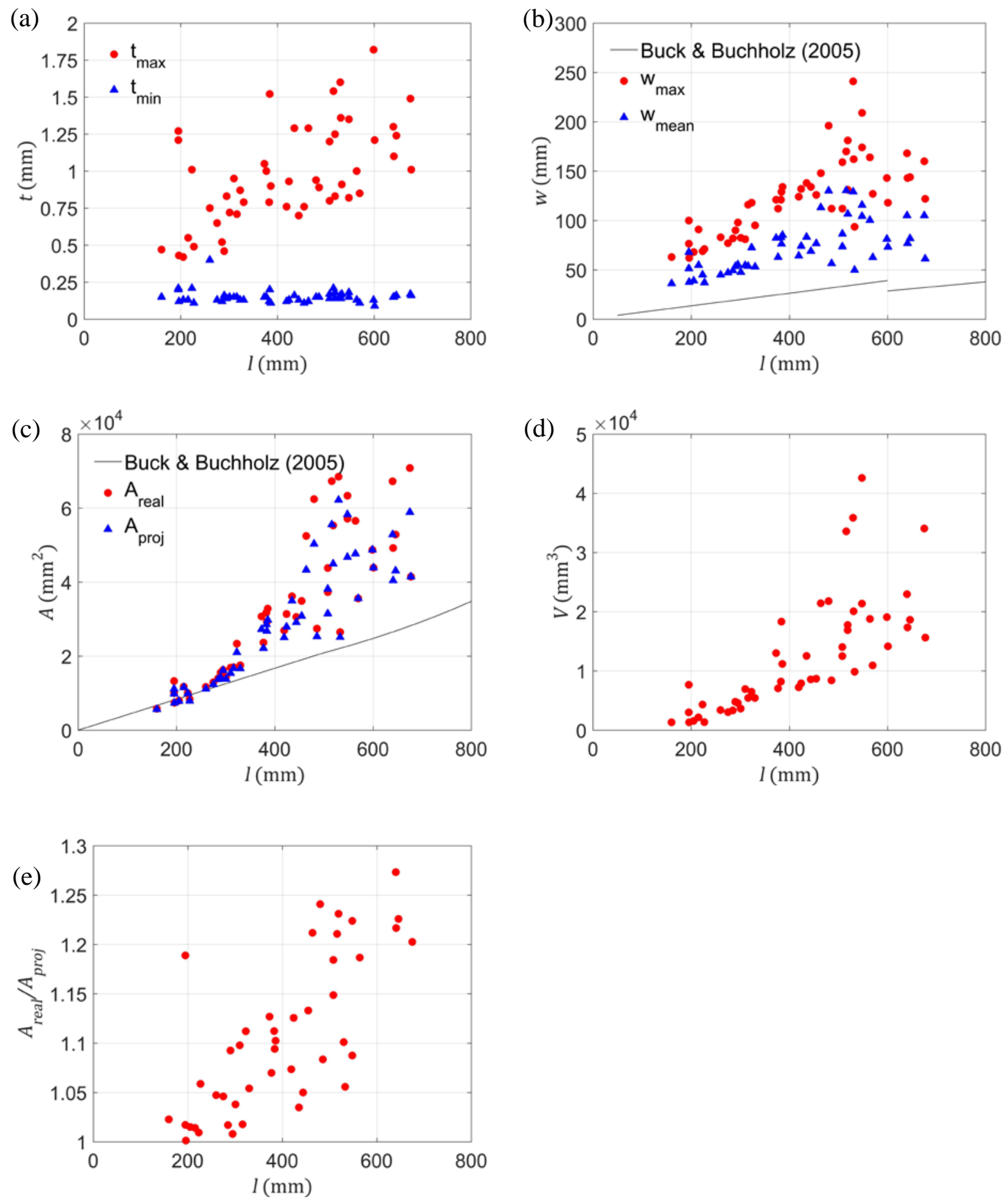

262 Fig. 4 Relationships between the blade length $l$ and: the maximum $t_{\max }$ and minimum $t_{\min }$ thicknesses (a); the maximum $w_{\max }$

263 and average $w_{\text {mean }}$ widths (b); the full-one-side (real) $A_{\text {real }}$ and projected $A_{\text {proj }}$ surface areas (c); the blade volume $V$ (d); and the level of undulation $A_{\text {real }} / A_{\text {proj }}$ (e). In (b) and (c) the black lines represent the regressions reported in Buck and Buchholz

265 (2005) to describe blade width and surface area as a function of blade length. In (b), (c), and (d) data show a narrow collapse for blades shorter than $400 \mathrm{~mm}$, while data points are distributed in a broad range for longer blades. (2 columns) 
The ratio of the blade full-one-side $A_{\text {real }}$ surface area to its projected $A_{\text {proj }}$ surface

268

269

270

271

272

273

274

275

276

277

278

279

280

281

282

283

284

285

286

287

288

289

290

291

area, which describes the level of undulation of the blade (Koehl and Alberte, 1988), was also calculated. The relationship between the blade length and the level of undulation $A_{\text {real }} / A_{\text {proj }}$ (Fig. 4e) is in agreement with the results from the analysis of other morphological parameters: as the blades get longer, their morphology is more complex and they become more ruffled. This trend is characteristic of sheltered environments, while seaweed blades from exposed sites exhibit values of $A_{\text {real }} / A_{\text {proj }}$ very close to unity (Koehl and Alberte, 1988).

Some common morphological features were identified among the seaweed blades investigated in the present study. Blade thickness varied significantly both across and along the blades. The central fascia was up to 10 times thicker than the edges (Fig. 4a). The maximum thickness was always found at the centre of the blade in proximity of the intercalary meristem. The minimum thickness was measured at the edges, typically at a distance of $0.25 l$ from the juncture of stipe and blade. Also, blade width varied along blade length, with the maximum width being usually located at $0.25 l$ from the juncture of stipe and blade. It is also noted that undulated/ruffled edges were mainly within the upstream part of the blade (i.e. close to the stipe), rather than towards the distal end. As a consequence, blades showed a 'stretched droplet' shape, bumped close to the stipe and streamlined towards the distal end (Fig. 5b). Seaweed blades characterised by ruffled edges also presented antisymmetric waving in their central fascia (Fig. 5a). These features are referred to as 'bullations' in phycology (Bold and Wynne, 1985) and have been reported for blades of $S$. latissima in Druehl and Kaneko (1973) and Lüning et al. (1978). Bullations started at the stipe-blade transition and spanned a good portion of the blade length. Interestingly, bullations were present only within blade parts characterised by ruffled edges, while they were not visible on streamlined parts. It is likely that bullations develop as a consequence of vertical 
oscillations of the edges, harmonizing their waving with the flow and acting as links between the edges and the central fascia. The particular shape of the blades and the patterns in their morphology could optimize the trade-off between drag and dynamic reconfiguration (similar to freshwater plants, Siniscalchi and Nikora, 2013). In a sheltered habitat where mean flow velocity is as low as $10 \mathrm{~cm} / \mathrm{s}$ (Table 1 ), dynamic reconfiguration is crucial to minimize light

297 limitation, particularly within a patch.
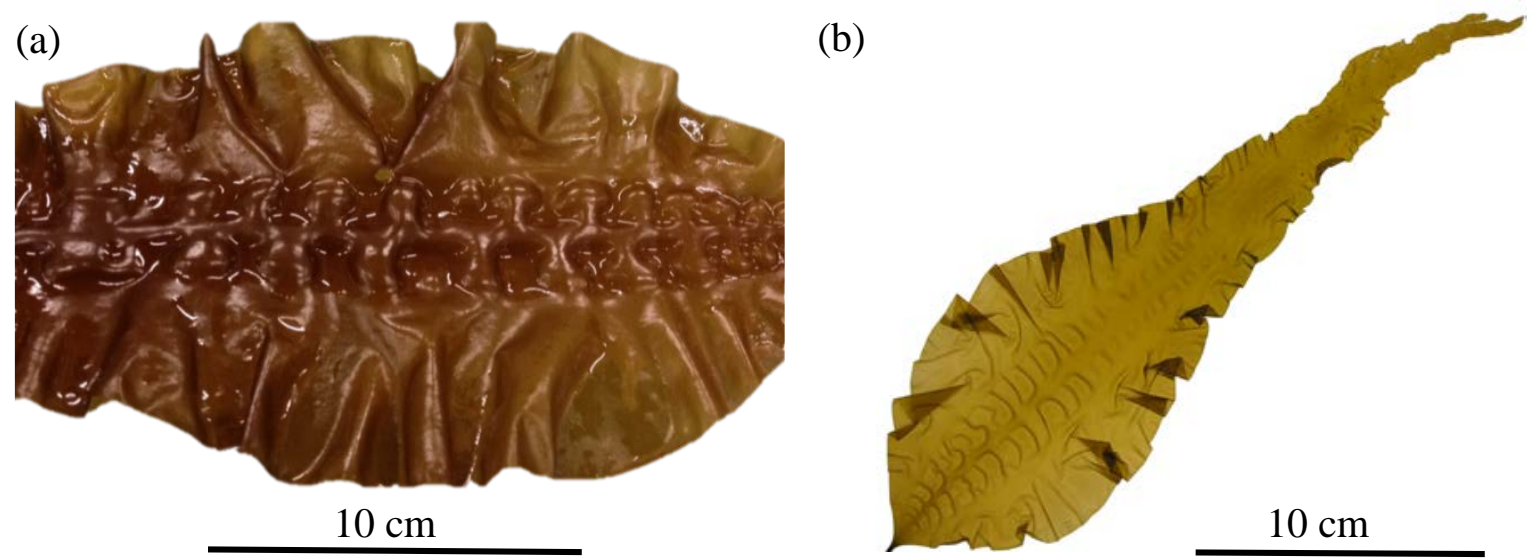

Fig. 5 Detail of seaweed blade showing ruffled edges and bullations in the central fascia (a). A seaweed blade showing the 'stretched droplet' shape (b). (2 columns)

\subsection{Mechanical properties of blade tissues}

301 As described in section 2.3, a number of biomechanical parameters were calculated for seaweed blade tissues. The density of algal material was estimated from weight (obtained using a weighing scale) and volume (measured as the volume of water displaced by an

304 immersed blade) of 50 seaweed blades. Its mean value is equal to $1092 \mathrm{~kg} / \mathrm{m}^{3}$, with a coefficient of variation of $8.3 \%$. In other words, seaweeds are slightly heavier than seawater.

306 The mean density is consistent with the values reported in the previous studies (Table 2), while the standard deviation cannot be compared due to lack of information in the literature.

Tensile $E_{t}$ and bending $E_{b}$ Young's moduli were estimated from data collected during 
310 about 40 tensile tests. Due to the appropriate length of specimen required for Peirce's test to

311 be successfully conducted (see section 2.3), the estimate of bending Young's modulus was

312 obtained from 14 specimens only. As a result, the coefficient of variation associated with the

313 estimate of $E_{b}(73 \%)$ is higher than that associated with the estimate of $E_{t}$ (38\%). The mean

314 values of Young's moduli are close to each other, with $E_{t}$ being estimated to be $4.7 \mathrm{MPa}$ and

$315 E_{b}$ to be 3.7 MPa (Table 2). This suggests a reasonable degree of internal isotropy in seaweed

316 blade tissues.

The estimate of bending Young's modulus calculated in the present study is compatible with the results for blades of L. digitata (Henry, 2014) obtained using Peirce's tests. The authors are not aware of any data on bending Young's modulus of S. latissima available in the literature. Tensile Young's modulus of S. latissima was estimated by Boller and Carrington (2007) using a small number of samples. The estimates of $E_{t}$ in the present study are lower than those reported by Boller and Carrington (2007). This does not appear to be due to a mechanical adaptation to environmental conditions (Harder et al., 2006; Hurd et al. 2014), but is believed to be related to other factors. The specimens tested by Boller and Carrington (2007) had a small length to width ratio (i.e. 3), making the results susceptible to end-wall effects. In addition, the different strain rates $(20 \mathrm{~mm} / \mathrm{min}$ vs $50 \mathrm{~mm} / \mathrm{min}$ ) of tensile tests may also account for the lower $E_{t}$ reported in the present study compared to the results in Boller and Carrington (2007). In fact, there is evidence that the use of a higher strain rate produces a higher $E_{t}$ in parenchymous tissues (Niklas, 1992). In general, it is visible from the data in Table 2 that the mean value of $E_{t}$ estimated in the present study is consistent with the findings for several other seaweed species (see references in Table 2). the elastic region of a stress-strain curve only (Fig. 6a). The upper limits of this region $\left(\varepsilon_{e}\right.$ 
336 good descriptor of material behaviour in a broad range of conditions (i.e. up to $0.8 \sigma_{b r}$ and

$3370.6 \varepsilon_{b r}$ ). Differently from Harder et al. (2006), who identified two tensile Young's moduli in

338 specimens from seaweed stipe, in the present study a linear elastic region is found only within

339 the initial part of the stress-strain curves (see Fig. 6a).

Table 2 Summary of estimates of the mechanical properties (density, elastic strain limit, elastic stress limit, tensile Young’s modulus, bending Young's modulus, breaking force, breaking strain, breaking stress, toughness) of algal material obtained in the present study compared with the data available in the literature for a number of seaweed species. Estimates from the present study are shown as mean value \pm standard deviation. (2 columns)

\begin{tabular}{|c|c|c|c|c|c|c|c|c|c|c|}
\hline Species & $\begin{array}{c}\rho_{s} \\
\left(\mathrm{~kg} / \mathrm{m}^{3}\right)\end{array}$ & $\begin{array}{c}\varepsilon_{e} \\
(\%)\end{array}$ & $\begin{array}{c}\sigma_{e} \\
(\mathrm{MPa})\end{array}$ & $\begin{array}{c}E_{t} \\
(\mathrm{MPa})\end{array}$ & $\begin{array}{c}E_{b} \\
(\mathrm{MPa})\end{array}$ & $\begin{array}{l}F_{b r} \\
(\mathrm{~N})\end{array}$ & $\begin{array}{l}\varepsilon_{b r} \\
(\%)\end{array}$ & $\begin{array}{c}\sigma_{b r} \\
(\mathrm{MPa})\end{array}$ & $\begin{array}{c}U \\
(\mathrm{MPa})\end{array}$ & Reference \\
\hline$\underline{\text { S. latissima }}$ & $\underline{1092 \pm 91}$ & $\underline{15 \pm 6}$ & $\begin{array}{l}\underline{0.67 \pm} \\
\underline{0.23}\end{array}$ & $\begin{array}{l}\underline{4.71 \pm} \\
\underline{1.81}\end{array}$ & $\begin{array}{l}\underline{3.73 \pm} \\
\underline{2.71}\end{array}$ & $\begin{array}{l}\underline{3.83 \pm} \\
\underline{2.14}\end{array}$ & $\underline{25 \pm 12}$ & $\begin{array}{c}\underline{0.84 \pm} \\
\underline{0.31}\end{array}$ & $\begin{array}{c}\underline{0.14 \pm} \\
\underline{0.1}\end{array}$ & Present study \\
\hline n/a. & 1050 & $\mathrm{n} / \mathrm{a}$ & $\mathrm{n} / \mathrm{a}$ & $\mathrm{n} / \mathrm{a}$ & $\mathrm{n} / \mathrm{a}$ & $\mathrm{n} / \mathrm{a}$ & $\mathrm{n} / \mathrm{a}$ & $\mathrm{n} / \mathrm{a}$ & $\mathrm{n} / \mathrm{a}$ & $\begin{array}{l}\text { Gaylord and Denny, } \\
1997\end{array}$ \\
\hline $\mathrm{n} / \mathrm{a}$ & 1025 & $\mathrm{n} / \mathrm{a}$ & $\mathrm{n} / \mathrm{a}$ & $\mathrm{n} / \mathrm{a}$ & $\mathrm{n} / \mathrm{a}$ & $\mathrm{n} / \mathrm{a}$ & $\mathrm{n} / \mathrm{a}$ & $\mathrm{n} / \mathrm{a}$ & $\mathrm{n} / \mathrm{a}$ & Gaylord et al., 2001 \\
\hline A. esculenta & $\mathrm{n} / \mathrm{a}$ & $\mathrm{n} / \mathrm{a}$ & $\mathrm{n} / \mathrm{a}$ & 1.2 & $\mathrm{n} / \mathrm{a}$ & 8.9 & 51 & 1.4 & 0.3 & Hale, 2001 \\
\hline A. esculenta & 862 & $\mathrm{n} / \mathrm{a}$ & $\mathrm{n} / \mathrm{a}$ & $\mathrm{n} / \mathrm{a}$ & $\mathrm{n} / \mathrm{a}$ & $\mathrm{n} / \mathrm{a}$ & $\mathrm{n} / \mathrm{a}$ & $\mathrm{n} / \mathrm{a}$ & $\mathrm{n} / \mathrm{a}$ & Paul et al., 2014 \\
\hline A. marginata & $\mathrm{n} / \mathrm{a}$ & $\mathrm{n} / \mathrm{a}$ & $\mathrm{n} / \mathrm{a}$ & $\mathrm{n} / \mathrm{a}$ & $\mathrm{n} / \mathrm{a}$ & $\mathrm{n} / \mathrm{a}$ & 30 & 2.9 & $\mathrm{n} / \mathrm{a}$ & Krumhansl et al., 2015 \\
\hline E. arborea & $\mathrm{n} / \mathrm{a}$ & $\mathrm{n} / \mathrm{a}$ & $\mathrm{n} / \mathrm{a}$ & 6.4 & $\mathrm{n} / \mathrm{a}$ & 11.9 & 42 & 2.1 & 0.6 & Hale, 2001 \\
\hline F. serratus & 1486 & $\mathrm{n} / \mathrm{a}$ & $\mathrm{n} / \mathrm{a}$ & $\mathrm{n} / \mathrm{a}$ & $\mathrm{n} / \mathrm{a}$ & $\mathrm{n} / \mathrm{a}$ & $\mathrm{n} / \mathrm{a}$ & $\mathrm{n} / \mathrm{a}$ & $\mathrm{n} / \mathrm{a}$ & Paul et al., 2014 \\
\hline F. vesiculosus & 840 & $\mathrm{n} / \mathrm{a}$ & $\mathrm{n} / \mathrm{a}$ & $\mathrm{n} / \mathrm{a}$ & $\mathrm{n} / \mathrm{a}$ & $\mathrm{n} / \mathrm{a}$ & $\mathrm{n} / \mathrm{a}$ & $\mathrm{n} / \mathrm{a}$ & $\mathrm{n} / \mathrm{a}$ & Paul et al., 2014 \\
\hline L. complanata & $\mathrm{n} / \mathrm{a}$ & $\mathrm{n} / \mathrm{a}$ & $\mathrm{n} / \mathrm{a}$ & $\mathrm{n} / \mathrm{a}$ & $\mathrm{n} / \mathrm{a}$ & $\mathrm{n} / \mathrm{a}$ & 27 & 1.3 & $\mathrm{n} / \mathrm{a}$ & Krumhansl et al., 2015 \\
\hline L. digitata & $\mathrm{n} / \mathrm{a}$ & $\mathrm{n} / \mathrm{a}$ & $\mathrm{n} / \mathrm{a}$ & $\mathrm{n} / \mathrm{a}$ & 0.8 & $\mathrm{n} / \mathrm{a}$ & $\mathrm{n} / \mathrm{a}$ & $\mathrm{n} / \mathrm{a}$ & $\mathrm{n} / \mathrm{a}$ & Henry, 2014 \\
\hline L. digitata & 1001 & $\mathrm{n} / \mathrm{a}$ & $\mathrm{n} / \mathrm{a}$ & $\mathrm{n} / \mathrm{a}$ & $\mathrm{n} / \mathrm{a}$ & $\mathrm{n} / \mathrm{a}$ & $\mathrm{n} / \mathrm{a}$ & $\mathrm{n} / \mathrm{a}$ & $\mathrm{n} / \mathrm{a}$ & Paul et al., 2014 \\
\hline L. setchelii & $\mathrm{n} / \mathrm{a}$ & $\mathrm{n} / \mathrm{a}$ & $\mathrm{n} / \mathrm{a}$ & 9.0 & $\mathrm{n} / \mathrm{a}$ & 22.3 & 33 & 2.3 & 0.3 & Hale, 2001 \\
\hline L. setchelii & $\mathrm{n} / \mathrm{a}$ & $\mathrm{n} / \mathrm{a}$ & $\mathrm{n} / \mathrm{a}$ & $\mathrm{n} / \mathrm{a}$ & $\mathrm{n} / \mathrm{a}$ & $\mathrm{n} / \mathrm{a}$ & 43 & 3.0 & $\mathrm{n} / \mathrm{a}$ & Krumhansl et al., 2015 \\
\hline L. sinclairii & $\mathrm{n} / \mathrm{a}$ & $\mathrm{n} / \mathrm{a}$ & $\mathrm{n} / \mathrm{a}$ & $\mathrm{n} / \mathrm{a}$ & $\mathrm{n} / \mathrm{a}$ & $\mathrm{n} / \mathrm{a}$ & 30 & 2.9 & $\mathrm{n} / \mathrm{a}$ & Krumhansl et al., 2015 \\
\hline M. pyrifera & $\mathrm{n} / \mathrm{a}$ & $\mathrm{n} / \mathrm{a}$ & $\mathrm{n} / \mathrm{a}$ & 5.4 & $\mathrm{n} / \mathrm{a}$ & 7.0 & 18 & 0.8 & 0.1 & Hale, 2001 \\
\hline M. pyrifera & $\mathrm{n} / \mathrm{a}$ & $\mathrm{n} / \mathrm{a}$ & $\mathrm{n} / \mathrm{a}$ & $\mathrm{n} / \mathrm{a}$ & $\mathrm{n} / \mathrm{a}$ & $\mathrm{n} / \mathrm{a}$ & 18 & 0.9 & $\mathrm{n} / \mathrm{a}$ & Krumhansl et al., 2015 \\
\hline P. fascia & $\mathrm{n} / \mathrm{a}$ & $\mathrm{n} / \mathrm{a}$ & $\mathrm{n} / \mathrm{a}$ & 7.3 & $\mathrm{n} / \mathrm{a}$ & $\mathrm{n} / \mathrm{a}$ & $\mathrm{n} / \mathrm{a}$ & $\mathrm{n} / \mathrm{a}$ & $\mathrm{n} / \mathrm{a}$ & $\begin{array}{l}\text { Boller and Carrington, } \\
2007\end{array}$ \\
\hline S. latissima & $\mathrm{n} / \mathrm{a}$ & $\mathrm{n} / \mathrm{a}$ & $\mathrm{n} / \mathrm{a}$ & 9.9 & $\mathrm{n} / \mathrm{a}$ & $\mathrm{n} / \mathrm{a}$ & $\mathrm{n} / \mathrm{a}$ & $\mathrm{n} / \mathrm{a}$ & $\mathrm{n} / \mathrm{a}$ & $\begin{array}{l}\text { Boller and Carrington, } \\
2007\end{array}$ \\
\hline S. sessilis & $\mathrm{n} / \mathrm{a}$ & $\mathrm{n} / \mathrm{a}$ & $\mathrm{n} / \mathrm{a}$ & $\mathrm{n} / \mathrm{a}$ & $\mathrm{n} / \mathrm{a}$ & $\mathrm{n} / \mathrm{a}$ & 52 & 1.9 & $\mathrm{n} / \mathrm{a}$ & Krumhansl et al., 2015 \\
\hline
\end{tabular}


A summary of the results of tensile tests up to the breakage point is shown in Table 2.

346 The breaking strain, breaking stress, and toughness are within the range of values reported in

347 the previous studies for a number of seaweed species. They are among the lowest values

348 reported for seaweeds, suggesting that blades of S. latissima are relatively flexible, and

349 cannot sustain high axial loads (i.e. they are weak in this respect). We should note here that

350 the force at breakage is not a useful parameter for comparison of different studies because it

351 is specimen size-dependent.

352

When a specimen was tested, the following phases typically occurred (Fig. 6a): (a)

353 there was a linear elastic response of the material with no visible variation in the crosssectional area of the specimen (up to elastic limits); (b) a localised reduction in the crosssectional area close to the centre of the specimen occurred, a phenomenon referred to as 'necking' (Niklas, 1992), and the response of the material was plastic; and (c) the specimen soon broke. The material of which S. latissima is made is ductile, as it shows plastic deformations after the elastic region, and exhibits a strain hardening behaviour, which is visible on the stress-strain curve plotted in Fig. 6a. This behaviour is common to many

360 biomaterials, such as silk and plant tissues (Niklas and Spatz, 2012). It implies that the 361 material can sustain further loading as the strain increases over the linear elastic region and is 362 linked to the re-alignment of tissues in the direction parallel to the uniaxial force. The shape 363 of the stress-strain curve (so called 'r-shape') also indicates that high values of stress, rather 364 than high strains, are critical for breakage of seaweed tissues. 

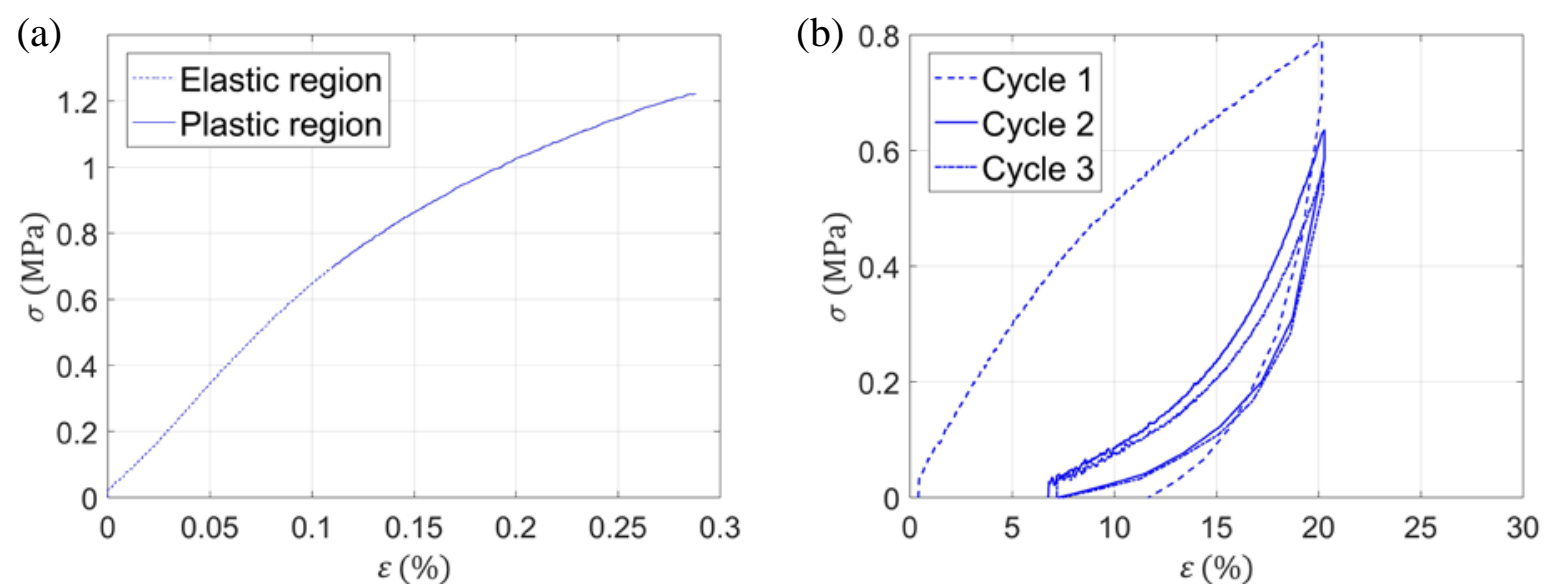

Fig. 6 Examples of stress-strain curves from a tensile test up to the breakage point (a) and a tensile cyclic loading-unloading test (3 cycles showed) (b). In (a) linear elastic region and plastic region are shown; (b) shows the changes in the stress-strain curve after the first loading. ( 2 columns)

Effects of tensile loading-unloading cycles on the properties of seaweed tissues are visible in the stress-strain curves in Fig. 6b. The curvature varies after the $1^{\text {st }}$ loading (Cycle 1), the curve changing from concave downward to concave upward, and the stress required to reach the same level of deformation decreases. A similar behaviour was reported by Hale 372 (2001) for algal materials from several seaweed species. In other words, the material loses 373 stiffness at small strains, while it becomes stiffer for values of strain close to the maximum previously experienced, resembling the trend shown by the previous unloading curve. The material does not recover completely from the applied strain and experiences permanent deformations. However, a part of these deformations is recovered between the end of the unloading phase and the beginning of the $2^{\text {nd }}$ loading cycle, which are separated by a time lag of a few seconds (time required to set up the testing machine), suggesting a viscoelastic behaviour of the material. After the $2^{\text {nd }}$ loading cycle, the stress-strain curves do not appear to change significantly. the values of the elastic hysteresis, degree of elasticity, and energy ratio of each cycle (Table 
383 3). The elastic hysteresis $E_{c y c l e}$ decreases significantly between the $1^{\text {st }}$ and $2^{\text {nd }}$ cycles, result

384 that is apparent in Fig. 6b. A decrease in elastic hysteresis indicates that the specimen

385 dissipates a lower amount of energy after the $1^{\text {st }}$ cycle. The degree of elasticity $E_{\varepsilon}$ does not 386 vary significantly between the $1^{\text {st }}$ and $2^{\text {nd }}$ cycles (ANOVA, $\mathrm{P}=0.087$; variances homogenous:

387 Levene's test, $\mathrm{P}=0.79$ ). This result is somewhat unexpected, as most plastic deformations

388 occur during the $1^{\text {st }}$ cycle. However, the values of $E_{\varepsilon}$ are biased as, by definition, the original

389 length of the specimen is taken into account for the calculation of $E_{\varepsilon}$ in every cycle (i.e. any

390 extension from the original length of the specimen accounts as a deformation). A more

391 appropriate approach is to consider only the deformations that extend the specimen beyond

392 its length at the beginning of each cycle (i.e. sum of its original length and plastic

393 deformations caused by the previous cycle). This way, $E_{\varepsilon}$ is very close to unity both in the $2^{\text {nd }}$

394 and $3^{\text {rd }}$ cycles, meaning that no plastic deformations occur after the $1^{\text {st }}$ cycle. The energy ratio

$395 E_{\text {ratio }}$ increases significantly between the $1^{\text {st }}$ and $2^{\text {nd }}$ cycles (ANOVA, $\mathrm{P}<<0.0001$; variances

396 homogenous: Levene's test, $\mathrm{P}=0.92$ ), indicating that the material enhances its ability to

397 release strain energy applied by external forces (i.e. it becomes more resilient). This variation

398 in resilience is linked to the fact the plastic deformations occur mainly during the $1^{\text {st }}$ cycle.

399 None of these parameters show significant variation between the $2^{\text {nd }}$ and $3^{\text {rd }}$ cycles, in

400 agreement with visual observation of the stress-strain curves. These results suggest that once

401 the material has experienced a certain level of strain it becomes more resilient, lowering the

402 chances of damages associated with that strain level. A higher resilience comes at the price of

403 the material experiencing plastic deformations that are not recoverable in the short term.

404 Nevertheless, permanent deformations that may occur due to extreme events or biotic factors

405 in a natural environment can be important to enhance organism growth (Niklas and Spatz, 406 2012). 

the results, very few data sets are available in the literature regarding tensile cyclic loadingunloading tests on algal material. According to the results in Hale (2001), the energy ratio for algal materials ranges from 0.15 to 0.43 for the $1^{\text {st }}$ cycle and from 0.62 to 0.89 for successive cycles. These values are compatible with the results from the present study (Table 3).

Table 3 Summary of estimates of mechanical properties (elastic hysteresis, degree of elasticity,

\begin{tabular}{lccc}
\hline & $\boldsymbol{E}_{\text {cycle }}\left(\boldsymbol{M J} / \boldsymbol{m}^{\mathbf{3}}\right)$ & $\boldsymbol{E}_{\boldsymbol{\varepsilon}}(-)$ & $\boldsymbol{E}_{\text {ratio }}(-)$ \\
\hline Cycle 1 & $0.069 \pm 0.028$ & $0.497 \pm 0.067$ & $0.208 \pm 0.031$ \\
Cycle 2 & $0.015 \pm 0.006$ & $0.562 \pm 0.094$ & $0.527 \pm 0.030$ \\
Cycle 3 & $0.012 \pm 0.004$ & $0.620 \pm 0.062$ & $0.574 \pm 0.060$ \\
\hline
\end{tabular}

\subsection{Effects of blade length on its mechanical properties}

416

The mechanical properties of algal material were also analysed as a function of the blade length, by checking potential correlations between the blade length and the biomechanical parameters introduced in section 2.3. Almost all biomechanical parameters were found to be independent of the blade length, including material density, stress at breakage, and toughness. On the other hand, tensile Young's modulus $E_{t}$ (Fig. 7a) and resilience for the $2^{\text {nd }}$ and $3^{\text {rd }}$ (Fig. 7b) cycles increase significantly with blade length. The regression lines, however, do not appear to be able to fully describe the broad variance shown by the data, particularly for $E_{t}\left(\mathrm{R}^{2}=0.18\right)$. The lack of correlation between the blade length and biomechanical parameters can be explained by considering the way in which specimens were prepared in the present study and findings reported in Krumhansl et al. (2015).

Growth in S. latissima occurs in the intercalary meristem, located in the transition region between the stipe and the blade (Bold and Wynne, 1985). Consequently, the newest material is close to the transition region and it gets older towards the distal end of the blade. 
429 Krumhansl et al. (2015) reported that mechanical properties of seaweed material vary 430 depending on its position along the blade and, as a consequence, on its age: tensile Young's 431 modulus and breaking stress increase with age, while breaking strain reduces. In the present 432 study, however, specimens were cut haphazardly from the central part of the blades, without 433 measuring the distance from the intercalary meristem. Biomechanical parameters of material 434 from long seaweed blades were characterised by high variance, which affected the 435 identification of correlations between the blade length and most of these parameters. The 436 natural tendency of aging materials to affect their mechanics (e.g. Niklas, 1992) is a plausible 437 explanation for this lack of correlation. However, this does not appear to be the case for 438 material density, which showed a homogenous variance across the range of blade lengths.
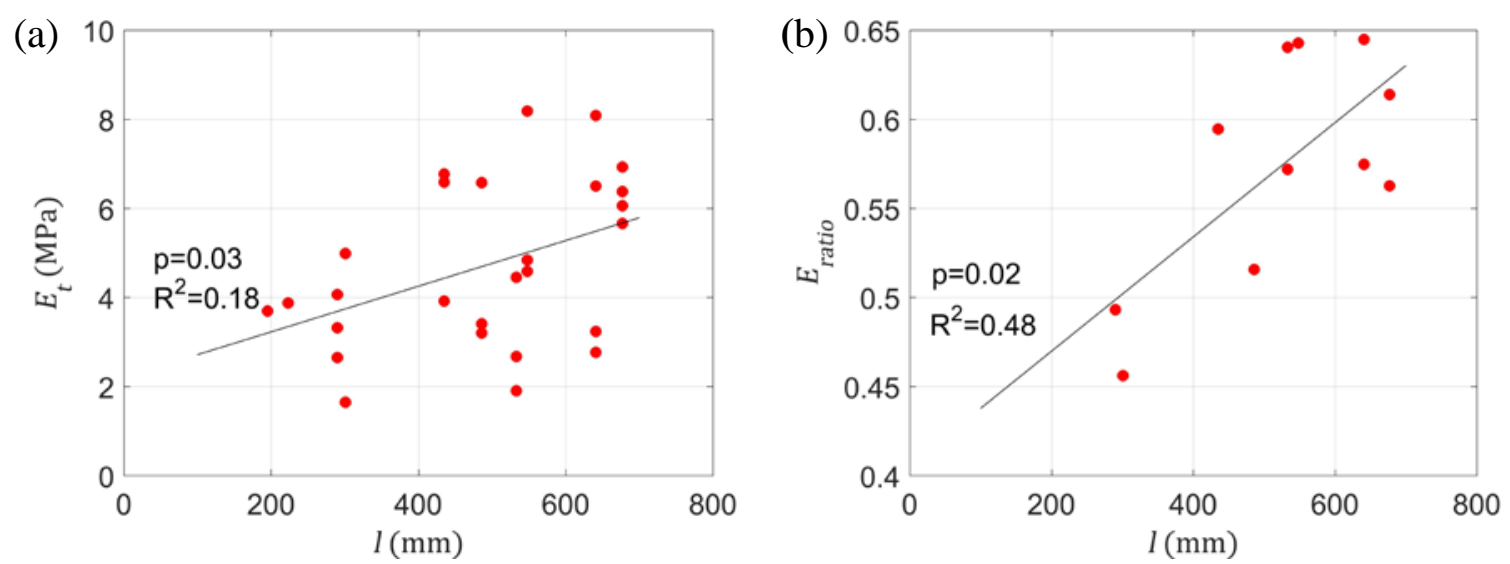

Fig. 7 Relationships between the blade length and tensile Young's modulus (a) and energy ratio for Cycle 3 (b). Both regression lines are significant (i.e. $\mathrm{p}<0.05$ ), however they do not describe most of the variance shown by the data. ( 2 columns)

\section{Conclusions}

The present study addresses the existing lack of knowledge on biomechanics and 444 morphology of vegetation living in coastal waters. In particular, the mechanical and morphological properties of S. latissima, a seaweed species widely distributed along the coasts of the North East Atlantic, were investigated. The morphology of seaweed blades is 
447 strongly influenced by the hydraulic conditions (i.e. phenotypic plasticity), showing a 448 particularly high variability among blades longer than $400 \mathrm{~mm}$. A common 'stretched 449 droplet' shape is reported for most blades, and may play a role in reducing the drag force 450 experienced by the seaweeds. understanding of seaweed interactions with the water flow were successfully estimated.

453 Samples of S. latissima are slightly heavier than seawater and their tissues are flexible, 454 allowing them to go with the flow passively. Algal material is ductile but weak, has a good 455 ability to recover from cyclic excitations and its tensile and bending Young's moduli have 456 similar values. The estimated values of the elastic limits indicate that tensile Young's modulus is an adequate descriptor of the mechanics of algal material in tension in a wide range of stresses and deformations that a blade may experience before breaking. On average, tissues from long seaweed blades are stiffer and more resilient than those from short blades.

460 However, in future studies the effect of blade length on mechanical properties should be 461 assessed taking into account the different ages of tissues along the blade.

The results from the current study can be used for designing physical models of 463 seaweeds to be tested for a number of applications (for example, to investigate the drag force 464 experienced by a seaweed patch, either artificial or natural). This study is also helpful for the 465 development of numerical models involving flow-vegetation interactions, providing 466 information (i.e. Young's modulus and density of seaweed material) required for predicting 467 seaweed motion. The other biomechanical parameters estimated can contribute to the understanding of seaweed mechanical response to physical stresses. 


\section{Acknowledgements}

470 The work described in this publication was conducted during the Ph.D. study of D. Vettori,

471 funded by the Northern Research Partnership. The authors thank Olivia McCabe for her 472 contribution to conducting morphological and mechanical tests, David Attwood and Hamish

473 Biggs for their assistance during seaweed collection and transport to the University of 474 Aberdeen.

\section{References}

476 Bardach, J. E., Ryther, J. H., McLarney, W. O., 1972. Aquaculture - The Farming and 477 Husbandry of Freshwater and Marine Organisms. John Wiley and Sons, Inc., New York, $478 \quad 868$ pp.

479 480

481

482

483

484

485

486

487

488

489

490

Biedka, R. F., Gosline, J. M., and DeWreede, R. E., 1987. Biomechanical analysis of waveinduced mortality in the marine alga Pterygophora californica. Marine Ecology Progress Series, 36, 163-170.

Bold, H. C., and Wynne, M. J., 1985. Introduction to the Algae. Prentice-Hall, Inc., Englewood Cliffs, New Jersey, 720 pp.

Boller, M. L., and Carrington, E., 2007. Interspecific comparison of hydrodynamic performance and structural properties among intertidal macroalgae. The Journal of Experimental Biology, 210(11), 1874-1884.

Buck, B. H., and Buchholz, C. M., 2005. Response of offshore cultivated Laminaria saccharina to hydrodynamic forcing in the North Sea. Aquaculture, 250(3), 674-691.

Chan, C. X., Ho, C. L., and Phang, S. M., 2006. Trends in seaweed research. Trends in Plant Science, 11(4), 165-166. 
491 Chopin, T., and Sawhney, M., 2009. Seaweeds and their mariculture. The Encyclopedia of Ocean Sciences, 4477-4487.

493

494

495

496

497

498

499

500

501

502

503

504

505

506

507

508

509

510

511

512

Connell, B. S., and Yue, D. K., 2007. Flapping dynamics of a flag in a uniform stream. Journal of fluid mechanics, 581, 33-67.

Druehl, L. D., and Kaneko, T., 1973. On Laminaria saccharina from Hokkaido. Journal of Plant Research, 86(4), 323-327.

Fei, X., 2004. Solving the coastal eutrophication problem by large scale seaweed cultivation. Hydrobiologia, 512(1-3), 145-151.

Fonseca, M. S., and Koehl, M. A. R., 2006. Flow in seagrass canopies: the influence of patch width. Estuarine, Coastal and Shelf Science, 67(1), 1-9.

Gaylord, B., and Denny, M., 1997. Flow and flexibility. I. Effects of size, shape and stiffness in determining wave forces on the stipitate kelps Eisenia arborea and Pterygophora californica. Journal of Experimental Biology, 200(24), 3141-3164.

Gaylord, B., Hale, B. B., and Denny, M. W., 2001. Consequences of transient fluid forces for compliant benthic organisms. Journal of Experimental Biology, 204(7), 1347-1360.

Gerard, V. A., 1987. Hydrodynamic streamlining of Laminaria saccharina Lamour in response to mechanical stress. Journal of Experimental Marine Biology and Ecology, 107(3), 237-244.

Hale, B. B., 2001. Macroalgal materials: foiling fracture and fatigue from fluid forces. Ph.D. thesis, Stanford University, California.

Harder, D. L., Hurd, C. L., and Speck, T., 2006. Comparison of mechanical properties of four large, wave-exposed seaweeds. American Journal of Botany, 93(10), 1426-1432. 
513 Henry, P. Y. T., 2014. Bending properties of a macroalga: Adaptation of Peirce's cantilever 514 test for in situ measurements of Laminaria digitata (Laminariaceae). American Journal 515 of Botany, 101(6), 1050-1055.

516 Hounsfield Test Equipment, 1997. S-Series operating instructions. UK.

517 Hughes, A. D., Kelly, M. S., Black, K. D., and Stanley, M. S., 2012. Biogas from 518 macroalgae: is it time to revisit the idea. Biotechnology for Biofuels, 5(86), 1-7.

519 Hurd, C. L., and Pilditch, C. A., 2011. Flow-induced morphological variations affect diffusion boundary-layer thickness of Macrocystis pyrifera (Heterokontophyta, laminariales). Journal of Phycology, 47(2), 341-351.

Hurd, C. L., Harrison, P. J., Bischof, K., and Lobban, C. S., 2014. Seaweed ecology and 523 physiology. Cambridge University Press, New York, 551 pp.

James, M.A., 2010. A review of initiatives and related R\&D being undertaken in the UK and internationally regarding the use of macroalgae as a basis for biofuel production and other non-food uses relevant to Scotland. Report commissioned by the Marine Scotland, 79pp [online] Available at: http://www.gov.scot/Resource/Doc/295194/0115064.pdf

Koehl, M. A. R., and Alberte, R. S., 1988. Flow, flapping, and photosynthesis of Nereocystis [accessed 17/04/2015] shapes suited to different flow regimes: a new wrinkle. Integrative and Comparative Biology, 48(6), 834-851. 
Krumhansl, K. A., Demes, K. W., Carrington, E., and Harley, C. D., 2015. Divergent growth strategies between red algae and kelps influence biomechanical properties. American Journal of Botany, 102(11), 1938-1944.

Lamprianidou, F., Telfer, T., and Ross, L. G., 2015. A model for optimization of the productivity and bioremediation efficiency of marine integrated multitrophic aquaculture. Estuarine, Coastal and Shelf Science, 164, 253-264.

Lucas, J. S., and Southgate, P. C., 2012. Aquaculture: Farming aquatic animals and plants. Wiley-Blackwell, Hoboken, New Jersey, 648 pp.

Lüning, K., Chapman, A. R., and Mann, K. H., 1978. Crossing experiments in the nondigitate complex of Laminaria from both sides of the Atlantic. Phycologia, 17(3), 293298.

Mata, L., Schuenhoff, A., and Santos, R., 2010. A direct comparison of the performance of the seaweed biofilters, Asparagopsis armata and Ulva rigida. Journal of Applied Phycology, 22(5), 639-644.

Miler, O., Albayrak, I., Nikora, V., and O’Hare, M., 2012. Biomechanical properties of aquatic plants and their effects on plant-flow interactions in streams and rivers. Aquatic Sciences, 74(1), 31-44.

Möller, I., Spencer, T., French, J. R., Leggett, D. J., and Dixon, M., 1999. Wave transformation over salt marshes: a field and numerical modelling study from North Norfolk, England. Estuarine, Coastal and Shelf Science, 49(3), 411-426.

Niklas, K. J., 1992. Plant biomechanics: an engineering approach to plant form and function. University of Chicago press, Chicago, Illinois, 622 pp. 
Niklas, K. J., and Spatz, H. C., 2012. Plant physics. University of Chicago Press, Chicago, 558 Illinois, 448 pp.

559 Nikora, V., 2010. Hydrodynamics of aquatic ecosystems: an interface between ecology, 560 biomechanics and environmental fluid mechanics. River Research and Applications, 561 26(4), 367-384.

Païdoussis, M. P., 1998. Fluid-Structure Interactions: Slender Structures and Axial Flow. Elsevier, Amsterdam, The Netherlands, 1585 pp.

Paul, M., Henry, P. Y., and Thomas, R. E., 2014. Geometrical and mechanical properties of 565 four species of northern European brown macroalgae. Coastal engineering, 84, 73-80.

Peirce, F. T., 1930. The "handle" of cloth as a measurable quantity. Journal of the Textile Institute Transactions, 21, T377-T416.

Ramos, E., Juanes, J.A., Galván, C., Neto, J.M., Melo, R., Pedersen, A., Scanlan, C., Wilkes, R., van den Bergh, E., Blomqvist, M., Karup, H.P., Heiber,W., Reitsma, J.M., Ximenes, M.C., Silió, A., Méndez, F., González, B., 2012. Coastal waters classification based on physical attributes along the NE Atlantic region. An approach for rocky macroalgae potential distribution. Estuarine, Coastal and Shelf Science, 112, 105-114.

Sánchez-González, J. F., Sánchez-Rojas, V., and Memos, C. D., 2011. Wave attenuation due to Posidonia oceanica meadows. Journal of Hydraulic Research, 49(4), 503-514.

Sanderson, J. C., 2006. Reducing the environmental impact of seacage fish farming through Institute. 
578 Schlichting, C. D., 1986. The evolution of phenotypic plasticity in plants. Annual review of $579 \quad$ Ecology and Systematics, 17(1), 667-693.

580 Siniscalchi, F., and Nikora, V., 2013. Dynamic reconfiguration of aquatic plants and its 581 interrelations with upstream turbulence and drag forces. Journal of Hydraulic Research, 582 51(1), 46-55.

583 Temmerman, S., Meire, P., Bouma, T.J. et al. 2013. Ecosystem-based coastal defence in the $584 \quad$ face of global change. Nature, 504(7478), 79-83.

585 Vettori, D., 2016. Hydrodynamic performance of seaweed farms: an experimental study at 586 seaweed blade scale. Ph.D. thesis, University of Aberdeen, UK.

587 Wargacki, A. J., Leonard, E., Win, M. N., Regitsky, D. D., Santos, C. N. S., Kim, P. B., 588 Cooper, S. R., Raisner, R. M., Herman, A., Sivitz, A. B., Lakshmanaswamy, A., 589 Kashiyama, Y., Baker, D., and Yoshikuni, Y., 2012. An engineered microbial platform 590 for direct biofuel production from brown macroalgae. Science, 335(6066), 308-313.

591 West-Eberhard, M. J., 1989. Phenotypic plasticity and the origins of diversity. Annual review 592 of Ecology and Systematics, 20(1), 249-278. 